\title{
Analysis of Enhanced Built-up and Bare Land Index (EBBI) in the Urban Area of Yangon, Myanmar
}

\author{
Tin, S. N. ${ }^{1,2}$ and Muttitanon, W. ${ }^{2}$ \\ ${ }^{1}$ Department of Building, Ministry of Construction, Naypyidaw, 15011, Myanmar \\ E-mail: sunandar.tin@student.mahidol.edu \\ ${ }^{2}$ Department of Civil and Environmental Engineering, Mahidol University, 73170, Thailand \\ E-mail: wutjanun.mut@mahidol.ac.th \\ DOI: https://doi.org/10.52939/ijg.v17i4.1957
}

\begin{abstract}
In planning and reviewing changes in the ground overview data, land distribution guidelines and identification of changes are critical. The availability of free global and historical satellite images offers a valuable resource for the built-up region to be continuously and accurately mapped and tracked year by year. For thirty years of data, this study uses Landsat images to obtain substantial and land spread data that is extremely useful for urban arrangement. This paper mainly focuses on the basic extraction of the built-up area for the urban planning area every five years from the satellite images of LANDSAT 5, 7,8 and Sentinel $2 A$ from USGS. The goal is to evaluate the year-by-year shift in the urban built-up area and to obtain the accuracy of the mapping of built-up and bare land areas in the study of the urban built-up trend from 1990 to 2020. In this research, GIS tools such as raster calculator and built-up region modeling are used to measure the indices that include the Enhanced Built-up and Bareness Index (EBBI), the Normalized Difference Builtup Index (NDBI) and the Urban Index (UI) or the Built-up Index (BUI). This study will therefore point out a variable approach to mapping traditional enhanced built-up and bare land changes (EBBI) automatically with simple indices and according to index outputs. The uncoordinated areas of land and population urbanization spread from areas and gradually the link between the expansion of urban land development and population growth has moved from weak positive to strong decoupling. The advantage of the method the enhanced built-up and bareness index (EBBI) can therefore be realized with the correlation of linear regression slightly expanded in 2020 over the last thirty years. The percentage of the outputs between the indexes and population rate was to use the entire spectral range of Landsat imageries which cause less spectral confusion between built-up area changes and higher accuracies compared to other indices. The modelling method was effective, quickly simple to implement, and can be used to find out the built-up area extraction.
\end{abstract}

\section{Introduction}

The rapid expansion of urban building land would lead to a decoupling of the economic development trend, and population growth has shown that urban land expansion and population growth have a longterm bidirectional causal relationship. We used remote sensing and population information comparing with the change index, the model of coordination degree, to further explore this relationship. The key outcomes were the growth of urban development land with clear geographic location characteristics. In recent decades, the rate of built-up areas has risen. In Yangon, the former capital and the most heavily crowded city in Myanmar, various problems have occurred in different territories, including a massive expansion of building expansion, highway exchanges, strong waste management, and flooding. Growth in the population contributes to increased use of water and energy and induces land surface changes, resulting in regional to global climate change and environmental degradation (Sertel et al., 2010). Throughout history, the increase in population densities and the expansion of urban areas, especially in metropolitan cities, have changed the shape of the earth's surface (Masek et al., 2000). The city has recently undergone urban transition processes that occurred at a later time than other cities in the area. It's also increasingly dealing with issues like marginalization, traffic, and redevelopment, all of which relate to that inequality rather than inclusive growth (Ettehadi et al., 2019). The lack of public engagement in the process of urban planning and decision-making is one of the major issues raised in this report. For decades, 
Myanmar's governments have struggled to resolve the situation to inclusive growth. This barrier to inclusive growth has troubled Myanmar's governments for decades, but it is particularly important for Yangon, which has been under pressure since Myanmar's political liberalization problem began in 2010 (JICA Annual Report, 2017). Despite being one of the least urbanized countries in mainland Southeast Asia, Yangon, with 5.2 million residents, is the country's largest populace density city, accounting for $10 \%$ of the country's total population and $35 \%$ of its urban population. For thirty years of data, this study uses Landsat images to obtain critical and solid land spread data that is extremely useful for urban arrangement. This paper focuses primarily on the basic extraction of the built-up area from LANDSAT satellite images for the urban planning area by downloading from the website of the United States Geological Survey (USGS, 2013).

The goal is to solve the above problem is to analyze the change of urban built-up area from year to year and to obtain the accuracy of the mapping of built-up and bare land areas in studying the pattern of urban built-up changes using the combination of bands of satellite images from 1990 to 2020. To obtain the high precision urban built-up field, the tools such as raster calculator, reclassify and composite bands are used to model and calculate the indices that include enhanced built-up and bareness index (EBBI), Normalized difference built-up index (NDBI), Urban index (UI) and Built-up index (BU). A significant fact in the development of human civilization is the exact and convenient investigation and use of land properties. Because of the rapid urbanization and human migration, the surface of the earth changes dramatically in terms of environmental, financial and aesthetic impacts on a local and global scale. In this way, analysis of land spread from beyond the planet is important for the world as a whole (Phiri, 2017). The aim of this analysis is to find the built-up area by modeling the satellite images for the last thirty years (every five years) and testing the accuracy of the results between the images.

\section{Study Area}

The study area, Yangon is a commercial capital of Myanmar and has a population of approximately 7.36 million. The area is $10276 \mathrm{~km}^{2}$ and is located in lower Myanmar along with the Yangon River between latitude $17^{\circ} 06^{\prime}$ to $16^{\circ} 35^{\prime} \mathrm{N}$ and longitude $95^{\circ} 58^{\prime}$ to $96^{\circ} 24^{\prime} \mathrm{E}$, east of the Ayeyarwady River delta. Yangon has a tropical monsoon climate with three distinct seasons. The summer is from March to the middle of May, the rainy season starts in the middle of May and ends in middle of October, and the winter season is from the middle of October to until the end of February. The rapid urbanization and accelerated development are occurring in Yangon. In this study, the built-up area is analysed for the Yangon city (including 33 districts) which locates under the management of the Yangon city development committee (YCDC, 2016). In addition, Yangon is the commercial city in Myanmar, and has recorded a rapid population growth over the past ten years (Regional EST forum, 2008). According to the 2014 census, the city had a population of 5.16 million and 7.13 million in 2019. The city's population grew sharply after 1948 as many people.

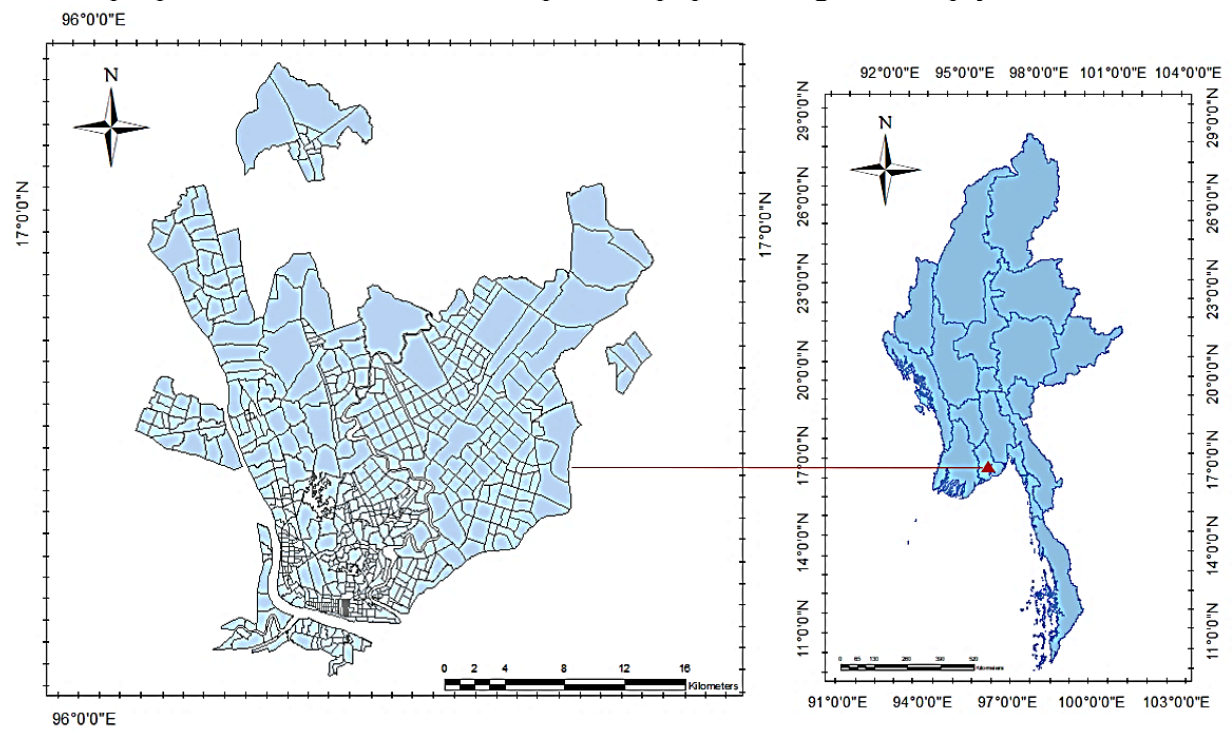

Figure 1: Location of the study area, Yangon City (Boundary under the Yangon City Development Committee, YCDC) 
The city's population grew sharply after 1948 as many people (mainly, the indigenous Burmese) from other parts of the country moved into the newly built satellite towns of North Okkalapa, South Okkalapa, and Thaketa in the 1950s and East Dagon, North Dagon and South Dagon in the 1990s. Yangon's population increased by 22.9 percent between 2000 and 2014 (JICA Annual Report, 2017) (Figure 1). The average population growth rate in Yangon between 1998 and 2011 was 2.58\% annually. The government's decision to move the nation's administrative capital to Naypyidaw has drained an unknown number of civil servants away from Yangon. It is difficult to know the exact numbers when it comes to the population of Yangon, but one thing that is known is that the expansion of its city limits over the past few decades have led to significant growth. Historical population Figures 2-3 show that the population hit half a million in 1941 before climbing $160 \%$ to over one million less than 10 years later. Each decade after saw significant population growth, ranging from $22.2 \%$ to $22.4 \%$ annually. The population is expected to surpass 5.3 million in 2020 before climbing to 5.9 million in 2025.

\section{Literature Review}

The high levels of urbanization due to the rapid population growth in the city are increasing because Yangon is one of the main activities of various sectors whether the trade of economy, historical, government buildings, industries and ports. Land growth urbanization data is one of the most significant assets for people.
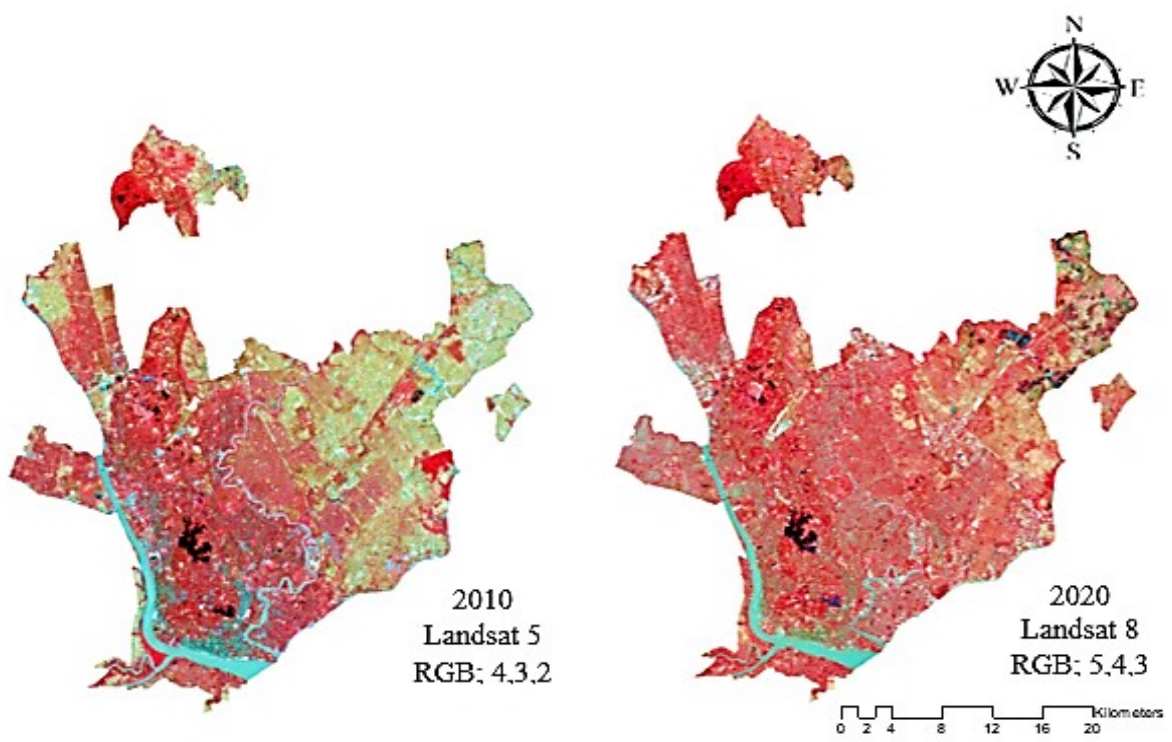

Figure 2: False colour composite images of 2010 and 2020, Yangon City

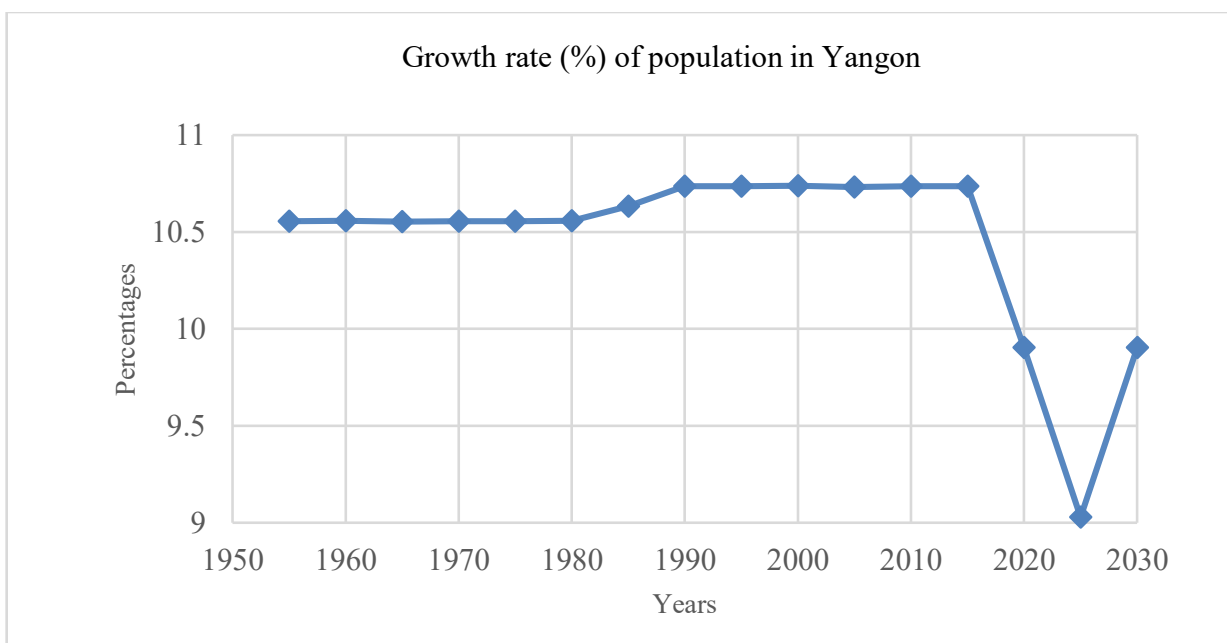

Figure 3: Increasing rate of population in Yangon (World population review-UN, Yangon population) 
Exact and convenient investigation and utilization of land assets assumes a significant fact in the advancement of human culture. Due to the fast urbanization and human movement, the world's surface changes significantly on a local and worldwide scales as to the environmental, financial and aesthetical impacts. The EBBI is the first builtup and bare ground index to simultaneously apply near infrared (NIR), short wave infrared (SWIR), and thermal infrared (TIR) channels. This new index was implemented in Denpasar (Bali, Indonesia) to differentiate built-up and bare land areas and had a high degree of accuracy compared to existing indices by As-syakur et al., (2012). It has also been able to differentiate between the number of built-up areas with a higher correlation than other indices used in urban areas. The three known spectral indices, namely NDBI, BAEI, and NDBaI was utilized for multispectral groups gained via Landsat 8 OLI sensor, Landsat- 8 imaginary obtained the built-up indices are explicit to feature built-up class in which useful in planning built-up area by Bramhe (2018).

\section{Data Collection Process}

The selection of satellite images is selected on the basis of some data acquired in different months in order to improve the data interpretation from the website (www.usgs.gov). The period of the time range is thirty years long imaginary for the study area. Therefore, the total of seven Landsat images were used for this study. The shape file of the boundary of the study area is downloaded from the Myanmar Information Management Unit (2020) which are legally data (published on February 11, 2020 on website) and reliable to use. There have two types of data collection that are the required imaginary and the shaped files of the boundary for the location of the study area which is under the management. The thinks of time detection for the study area were for the previous thirty years accordingly on every five years and therefore the collected Landsat imaginary were for 1990, 1995,
2000, 2005, 2010, 2015 and 2020 with universe transverse Mercator (UTM) projection zone $46 \mathrm{~N}$ as shown in Table 1. Satellites images with zero cloud cover in the study area were selected to minimize the negative impact of weather on the analysis, factors such as acquisition time, coverage, cloudiness, and also the resolution were considered. The remote sensing data utilized in this study were Landsat ETM+ data acquired from 1990 to 2020. (Landsat Science. Landsat 5, 1999 and Landsat 7, 2014). There have two types of data collection that are the required imaginary and the shaped files of the boundary for the location of the study area. The shape file of the boundary of the study area, which updated on February 2020 is downloaded from the Myanmar information management unit which are legally data and reliable to use. For the study area, the current metro area population and the previous population data is downloaded from the historical data sources of world population prospects, united nations.

\section{Methodology}

For this study, by the usage of Landsat remote sensing image data from USGS and the three models of analyzing built-up index are used for the combination of the current spatial resolution Landsat 7 channels (15 $\mathrm{m}$ resolution) with the multispectral Landsat 7 channels (30 m resolution), satellite data merging procedures have been implemented to improve the precision of the classification according to each decade for previous thirty years (Abler, 1988). The accuracy levels of the analyzed data performed using several remote sensing indices were compared to the distribution of built-up land areas of each index. A random sampling technique was used to collect sample pixels to compare the accuracy of the built-up extraction and bare land from different indices and to evaluate the difference between the outputs of them (Ellis, 2019). The spectral wavelength ranges and the spatial resolution bands of the data showed in Table 2 .

Table 1: Types of satellite data of the study area

\begin{tabular}{|c|c|c|c|}
\hline Type of Imaginary & Time & Resolution & Path/Row and Tile \\
\hline Landsat-5 TM & $\begin{array}{c}2^{\text {nd }} \text { April 1990 } \\
18^{\text {th }} \text { March 1995 } \\
25^{\text {th }} \text { March 2010 }\end{array}$ & $30 \mathrm{~m}$ & $130 / 48$ \\
\hline Landsat-7 ETM & $\begin{array}{c}3^{\text {rd }} \text { March 2000 } \\
13^{\text {th }} \text { April 2005 }\end{array}$ & $30 \mathrm{~m}$ & $130 / 48$ \\
\hline Landsat-8 OLI & $\begin{array}{c}30^{\text {th }} \text { March 2015 } \\
7^{\text {th }} \text { April 2020 }\end{array}$ & $30 \mathrm{~m}$ & $130 / 48$ \\
\hline Sentinel-2 MSI & $25^{\text {th }}$ April 2020 & $10 \mathrm{~m}$ & T46QHD \\
\hline
\end{tabular}


Table 2: The spatial resolution of bands of each satellite images Imaginary in this study area

\begin{tabular}{|c|c|c|c|c|c|}
\hline Bands & R/G/B & NIR & SWIR-1 & SWIR-2 & TIR \\
\hline Landsat-5 TM & $3 / 2 / 1$ & 4 & 5 & 7 & 6 \\
\hline Landsat-7 ETM & $3 / 2 / 1$ & 4 & 5 & 7 & 6 \\
\hline Landsat-8 OLI & $4 / 3 / 2$ & 5 & 6 & 7 & 11 \\
\hline Sentinel-2 MSI & $4 / 3 / 2$ & 8 & 11 & 12 & - \\
\hline
\end{tabular}

\subsection{Enhanced Built-up and Bareness Index (EBBI)}

The EBBI is a remote sensing index that applies bands of NIR, SWIR, and TIR. The NIR and SWIR bands are associated with a high contrast level for detecting built-up and bare land areas. In addition, in these bands, there is an inverse reflectance ratio with respect to detecting built-up or bare land areas (As-syakur et al., 2012).

$$
\mathrm{EBBI}=\frac{\text { SWIR }- \text { Red }}{\sqrt[10]{(\mathrm{SWIR}+\mathrm{TIR})}}
$$

Equation 1

\subsection{Normalized Difference Built-Up Index (NDBI)}

This index highlights urban areas where there is typically a higher reflectance in the shortwaveinfrared (SWIR) region, compared to the nearinfrared (NIR) region. (Zha et al., 2003). Negative value of NDBI represent water bodies whereas higher value represents build-up areas.

$$
\text { NDBI }=\frac{\text { SWIR }- \text { NIR }}{\text { SWIR }+ \text { NIR }}
$$

Equation 2

\subsection{Urban Index (UI)}

Urban built-up Index of area extraction from moderate spatial resolution Landsat time-series data is challenging because of significant intraurban heterogeneity and spectral confusion between other landcover types. (GIS resources, ndvi-ndbi-ndwi-ranges):

$$
\mathrm{UI}=\frac{\text { SWIR2 }- \text { NIR }}{\text { SWIR } 2+\text { NIR }}
$$

Eqaution 3

The shape file (polygons) of boundary for Yangon, which includes the 33 townships of the YCDC district was collected from Myanmar information management unit. The boundary polygons were digitized using sketch maps from the General Administration Department (GAD). After the classification of built-up area according to the tools in ArcMap, the imaginary of each years is exported to raster and reclassified to find the value of shaped area of built-up indices. The images of each years are combined as the tools of each models and then they are need to convert raster to polygon to know the indices of built-up indices of using models. For this purpose, the bands of multi-temporal (1990, 1995, 2000, 2005, 2010,2015 and 2020) Landsat satellite imagery and population data have been used to identify the increasing built-up index. In this data analyzing process as shown in Figure 4, applied the indices modelling in the raster calculator remote sensing techniques like normalized differences built-up index(NDBI), normalized differences bare land index (NDBaI) and enhanced built-up and bareness index(EBBI). Raster shapefiles were created physically to supply a base for the visual pictures in ARCMap utilizing both the initial band combination and the comes about of the directed classification in the field.

There are parts of records for the examination of built-up zone. Normalized Difference Built-up index (NDBI), Built-up index (BU), Urban index (UI), Improved Built-up, and Enhanced built-up and bareness index (EBBI) are the most common records for investigation the built-up regions. These diverse files having their possess equation, possess calculation strategy. Normalized Difference Bare land index (NDBaI) is to discover the exposed state area. The build-up zones and uncovered soil reflects more SWIR than NIR. Picture classification strategy (directed classification and unsupervised classification) is long and complex handle (Yi et al., 2014) It requires a compositive band \& applies numbers of operation for the ultimate result. The precision inferred from picture classification procedure depends on the images examiner and the strategy taken after the modelling. The output of pixel count numbers is used to analyze and calculate the area extraction of built-up by linear regression. The correlation of linear regression finds for each year and indices for all of the models to know the accurate built-up area. In any case, NDBI calculation is simple to analyze (Figure 4).

\section{Results for Modelling of Bands in Each Index}

Based on the data of results, the local significance of land utilization prompted area changes on surface environment brings up the issue of the legitimacy of discovery/attribution concentrates in specific zones where the maps of changes have been subsequent since previous 30 years to current times. 


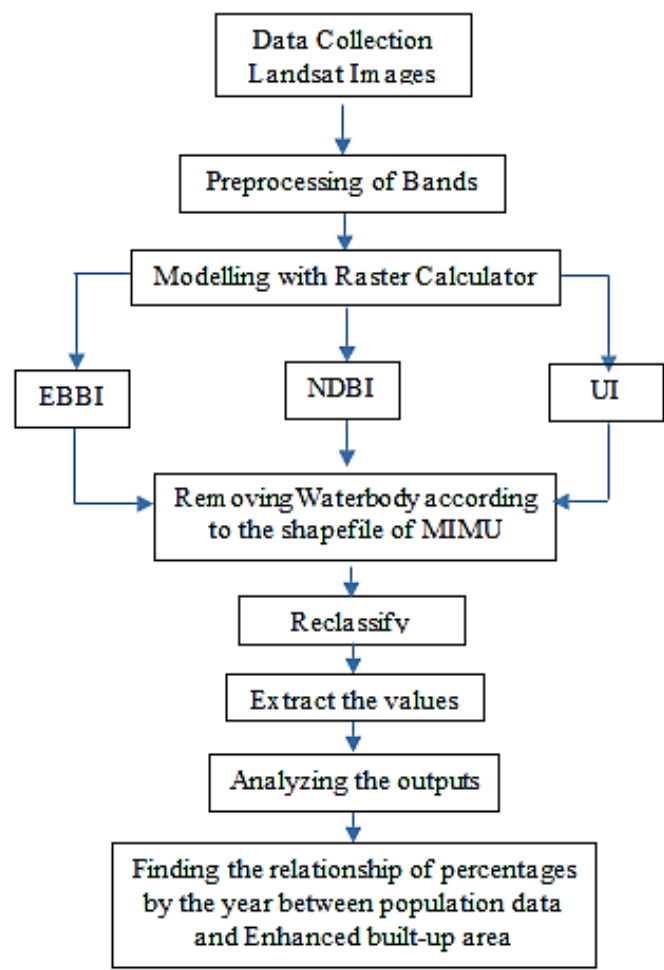

Figure 5: The flowchart of mapping method for this study

Difference Built-Up Index (NDBI), Built-Up Index (IBI) and Urban Index (UI) have been employed in the various modelling. The UI and NDBaI indices produced the built-up areas and simultaneously demarcated the wetland areas that may be due to the higher reflectance in SWIR contrasted with the NIR channel range in Figure 5. However, these indices are not always relevant in diverse complex heterogenous city. The EBBI index which principally utilizes groups of the NIR, SWIR, and TIR is eliminating of the NIR band from SWIR and adding the SWIR and TIR results by the partitioning of the distinction in basically zero water pixels as in Figure 6, just as negative and positive qualities for developed and uncultivated land pixels.In Normalized difference built-up index (NDBI), the build-up region and bare soil reflects more SWIR than NIR. As a result, higher values of Figure 7 showed the built-up area and NIR spectrum mapping process applies different data and spectral values based on the use category in each combining of bands. Land use mapping originally implemented the multispectral classification method; however, there are other methods that also utilize the application of the remote sensing index which classified urban land uses using several remote sensing indices (Bhatti and Tripathi, 2004).
The indices for mapping the built-up and bare land in urban areas such as the distinguishing built-up and bare-land regions, and improving the built-up density percentage of accuracy.The reflection is higher than SWIR spectrum reflection in the modelling of index.

Mapping the built-up and bare land in urban areas is important because the existence of these types of land can be used as an indicator of urban development and environmental quality. The Normalized difference built-up index (NDBI) and urban index (UI) are based on the high-speed mapping of built-up or bare land areas (Aziz, 2014). For the Figure 8, to be verified the assessment of the coverage of built-up and bareness area, the google earth pro is used for the starting from 2000, 2005, 2010, 2015 and 2020, was finding by the modelling of the indices that means automatically mapping. After the analyzing of the matching points, according to the results of Figures 8 and 9 shown the index accuracy for each Landsat form of the index property. The points (50 locations) are used to find in the checking for the built-up and bare land region from 2005 to 2020, the cause is for Landsat 7 (2005), Landsat 5 (2010), Landsat 8 (2015) and 2020) and Sentinel 2B for 2020 because the google earth pro can be seen for the study area the starting of the year of 2005. Therefore, the average of the checking accuracy is calculated according to the timeline and relevance of the data for the related of area on the google earth pro. According to the relative matching percentage of Landsat 8 and Sentinel images are more reliable in modelling with $84 \%$ and $93 \%$ respectively due to the Sentinel images are $10 \mathrm{~m}$ high resolution satellite images for 2020 (Figure 9).

However, the distribution between built-up and bare land areas for these two indices are inadequate to verify only the built-up area. In this study, remote sensing images were mainly classified into two types; built-up and bare land to approach the urban expansion. Following of the spectral pattern on each object, the logical method was applied to the spectral band that was combined with the index picture. Chen and Huang (2016) for example, used this approach in 2005. To isolate the built-up region entity, it was used combined operation (Band 5 Band4) $>0$, (Band $5-$ Band 6) $>0$ and $(0.33$ $>$ NDBI $>0.77)$, since there was only built-up with spectral value (Band 6- Band 5) $>0$, (Band $5-$ Band 6) $>0$. Later, the combined operation (Band 5 - Band 3) $>0$ and (Band $6-$ Band 4) $>0$ are used for water artifacts. 

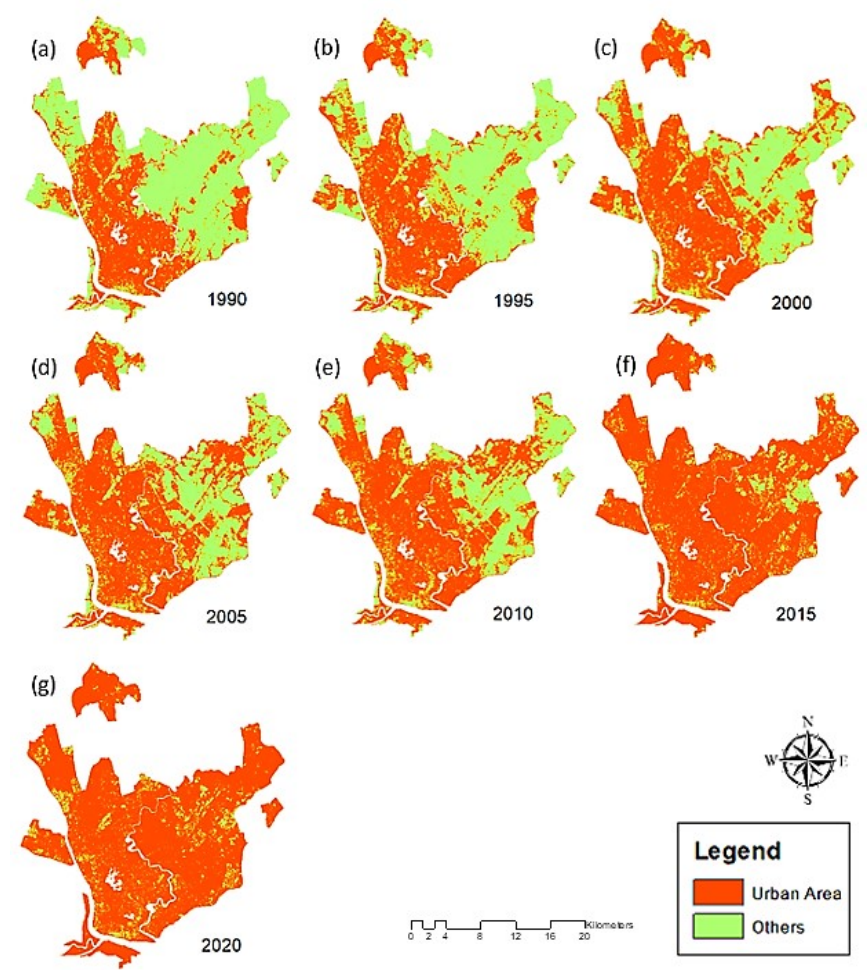

Figure 5: Urban Index (UI) of Landsat images in the study area (a)1990(b)1995(c)2000(d)2005(e)2010 (f)2015 (g)2020 (Descriptions: all positive values showed urban area)
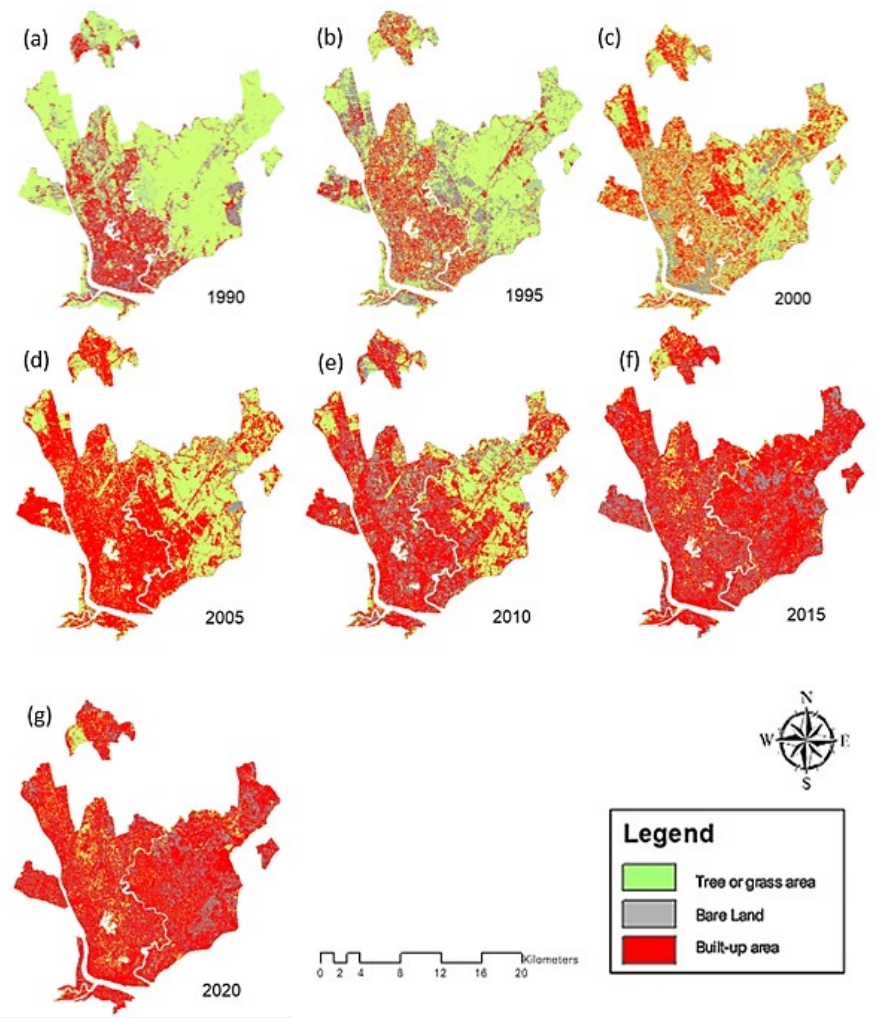

Figure 6: Enhanced Built-up and Bareness Index (EBBI) of Landsat images in the study area (a)1990 (b)1995 (c)2000 (d)2005 (e)2010 (f)2015 (g)2020 (Descriptions: -0.1 to 0.3 values showed urban built-up area and $>0.35$ values showed bare land area) 


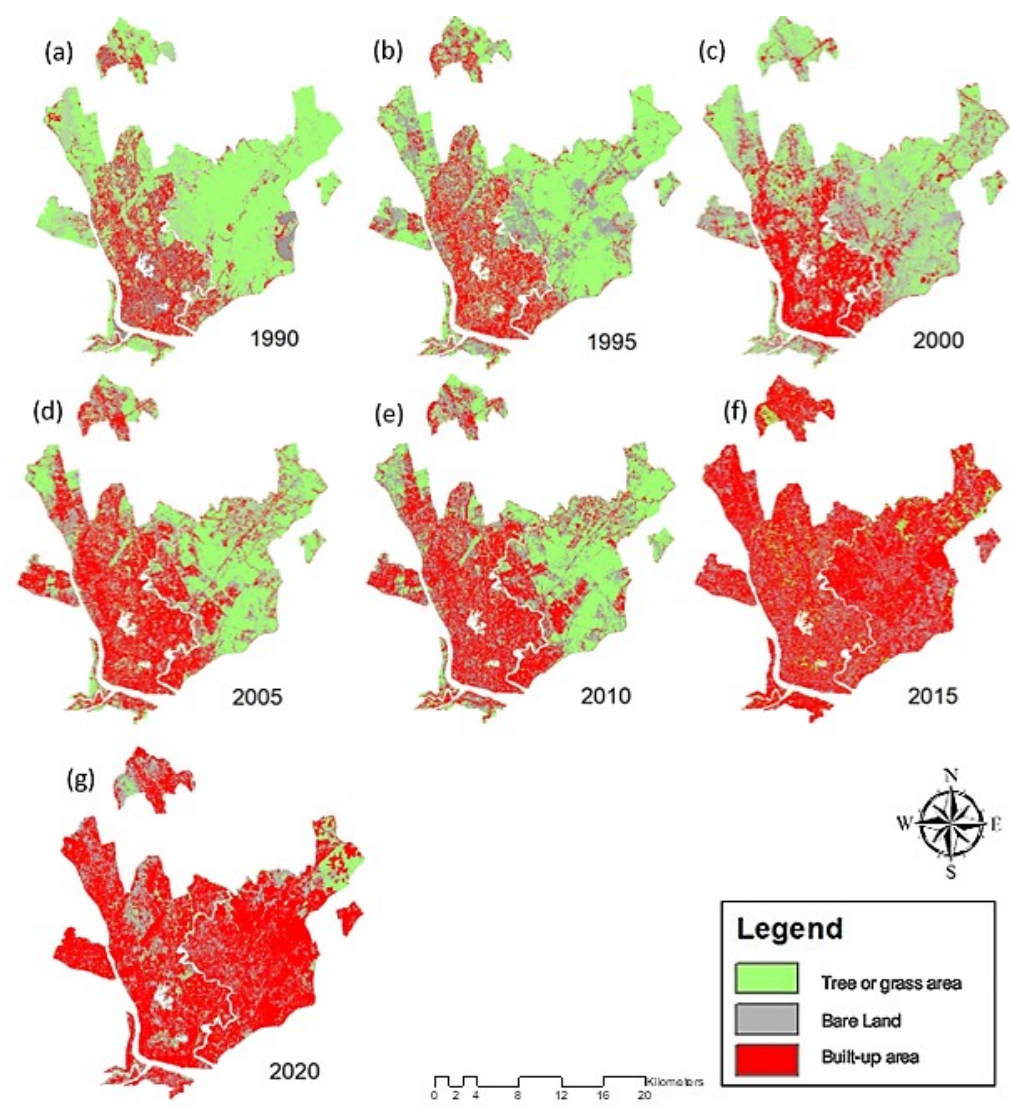

Figure 7: Normalized Difference Built-up index (NDBI) of Landsat images in the study area (a)1990 (b)1995 (c)2000 (d)2005 (e)2010 (f)2015 (g)2020 (Descriptions: all positive values showed built-up area)

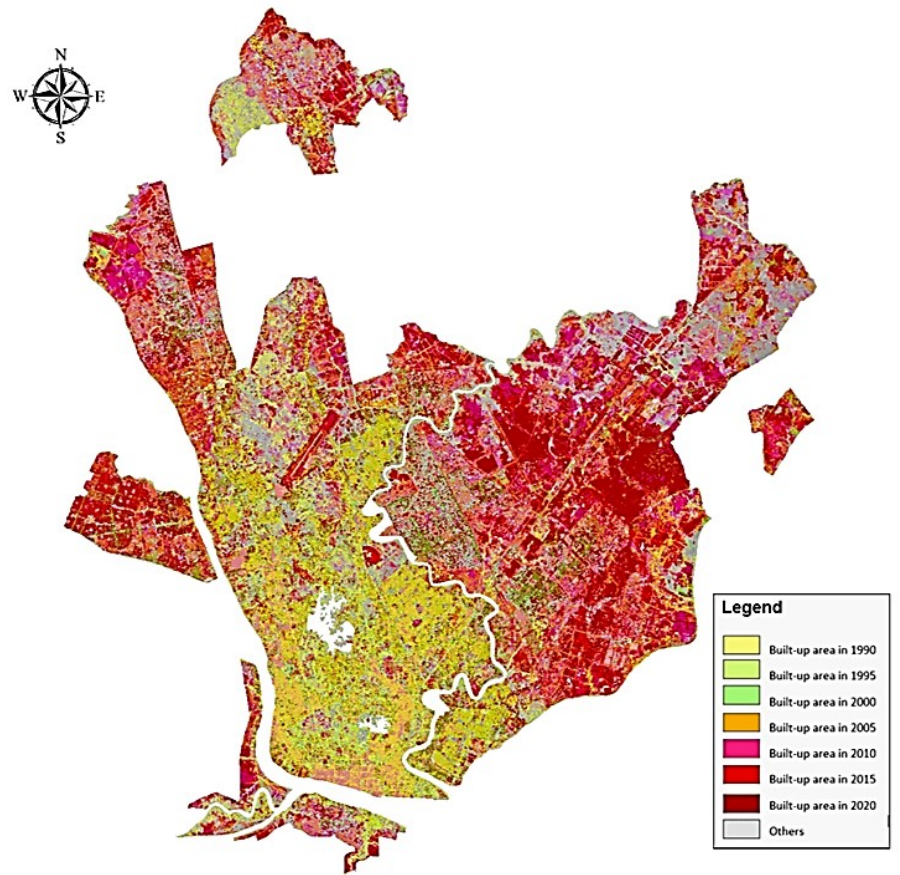

Figure 8: Changing of Enhanced Built-Up Index (EBBI) of Landsat images of the study area in every five years 

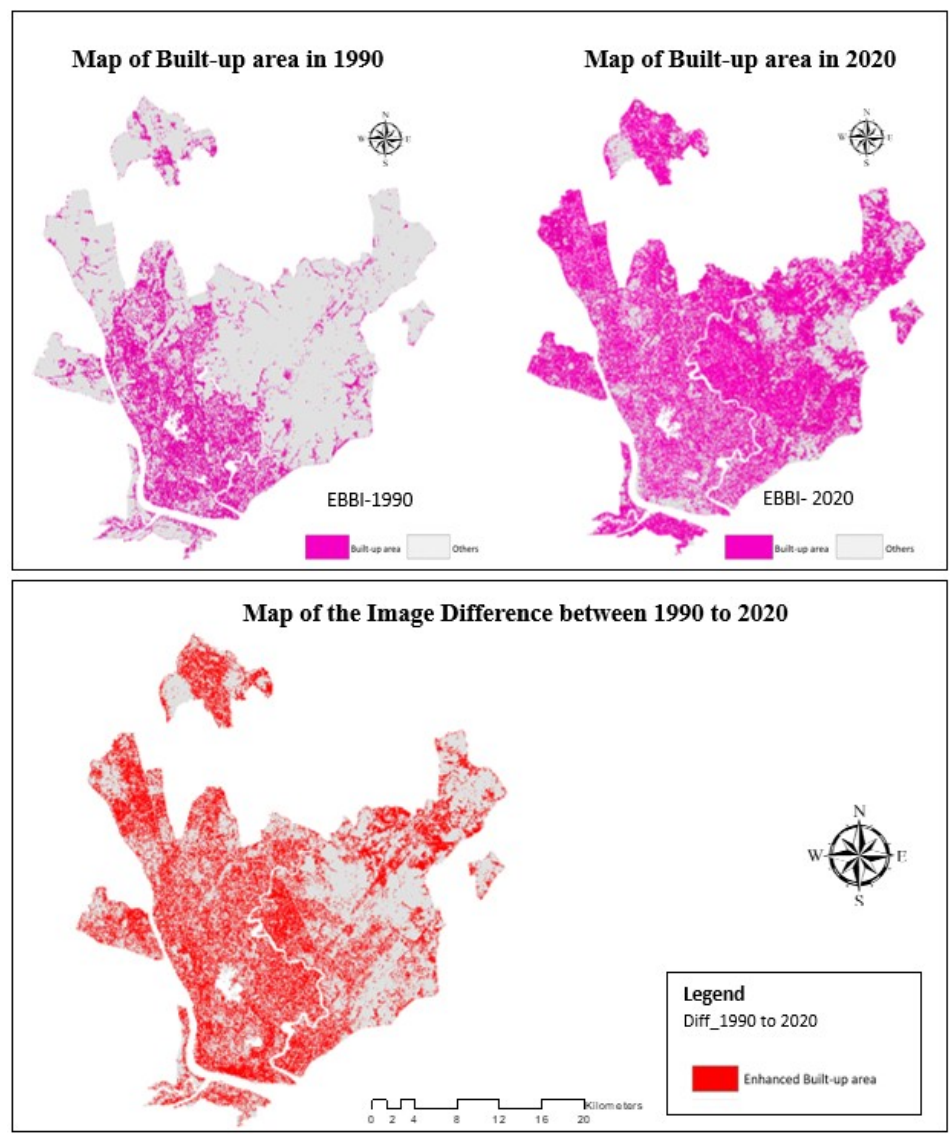

Figure 9: Change in built-up area in Yangon satellite from 1990 to 2020

Table 3: The percentage of built-up area of each index in this study area

\begin{tabular}{|c|c|c|c|c|}
\hline \multirow{2}{*}{ Years } & \multicolumn{2}{|c|}{$\begin{array}{c}\text { Percentage of Increasing Rate of Built-up } \\
\text { Area in each index (difference, \%) }\end{array}$} & \multirow{2}{*}{$\begin{array}{c}\text { Percentage of } \\
\text { Population } \\
\text { Increasing Rate (\%) }\end{array}$} \\
\cline { 2 - 4 } & UI & NDBI & EBBI & 9.671 \\
\hline 1995 & 6.884 & 2.072 & 1.200 & 9.712 \\
\hline 2000 & 1.927 & 1.219 & 7.564 & 9.681 \\
\hline 2005 & 3.791 & 1.603 & 9.930 & 9.701 \\
\hline 2010 & 1.737 & 6.014 & 6.192 & 9.696 \\
\hline 2015 & 12.634 & 1.786 & 4.066 & 9.011 \\
\hline 2020 & 2.946 & 3.129 & 3.919 & \\
\hline
\end{tabular}

For this reason, the build-up area and bare land classes, a modelling of EBBI, NDBI and UI index was used because when using spectral combinations, each band did not form substantially different classes, but when modelling of EBBI index, particularly for the open land class, a more suitable class was created. The operation $(-0.02$ $>\mathrm{EBBI}>0.04)$ and $(-1>\mathrm{UI}>1)$ were used for the bare land class, while the threshold $(-0.18>\mathrm{NDBI}>$ 0.3 ) was used for the build-up area.

\section{Outputs of the Data}

According to the Table 3, the annual percentages of the built-up area was significantly increasing between 2005 and 2015 of the study area and a slightly increasing occurred on the other years. The urban index (UI) shows the increasing of urban expanding area of numbers was the highest after 2010 to the 2015. According to the Figure 10, the outputs of the percentage of the built-up area in the three indexes of modelling showed the increasing rate of the urban area expansion within thirty years. The results of EBBI index might have more reliable correlation coefficient than the NDBI and UI index because of the modelling results of the NDBI and UI includes not only the built-up area but also the usage of urban expansion area. 


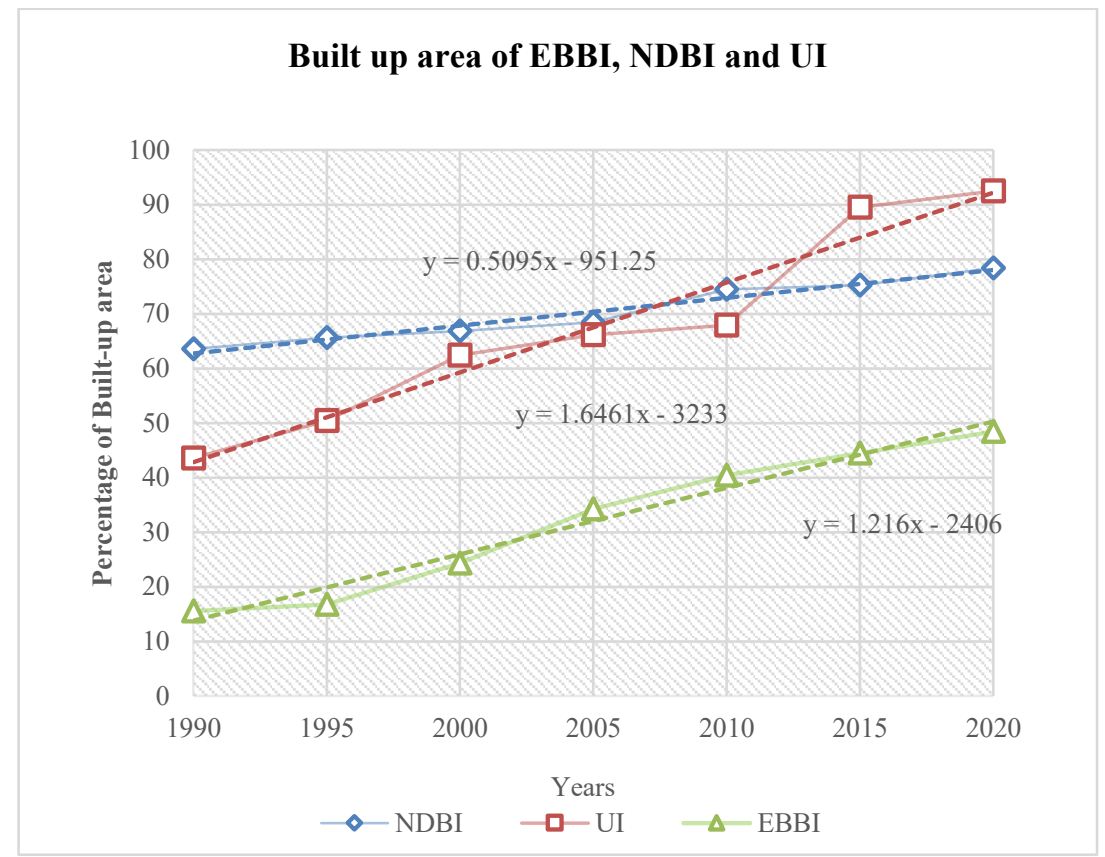

Figure 10: Percentage for the built-up area of EBBI, NDBI and UI

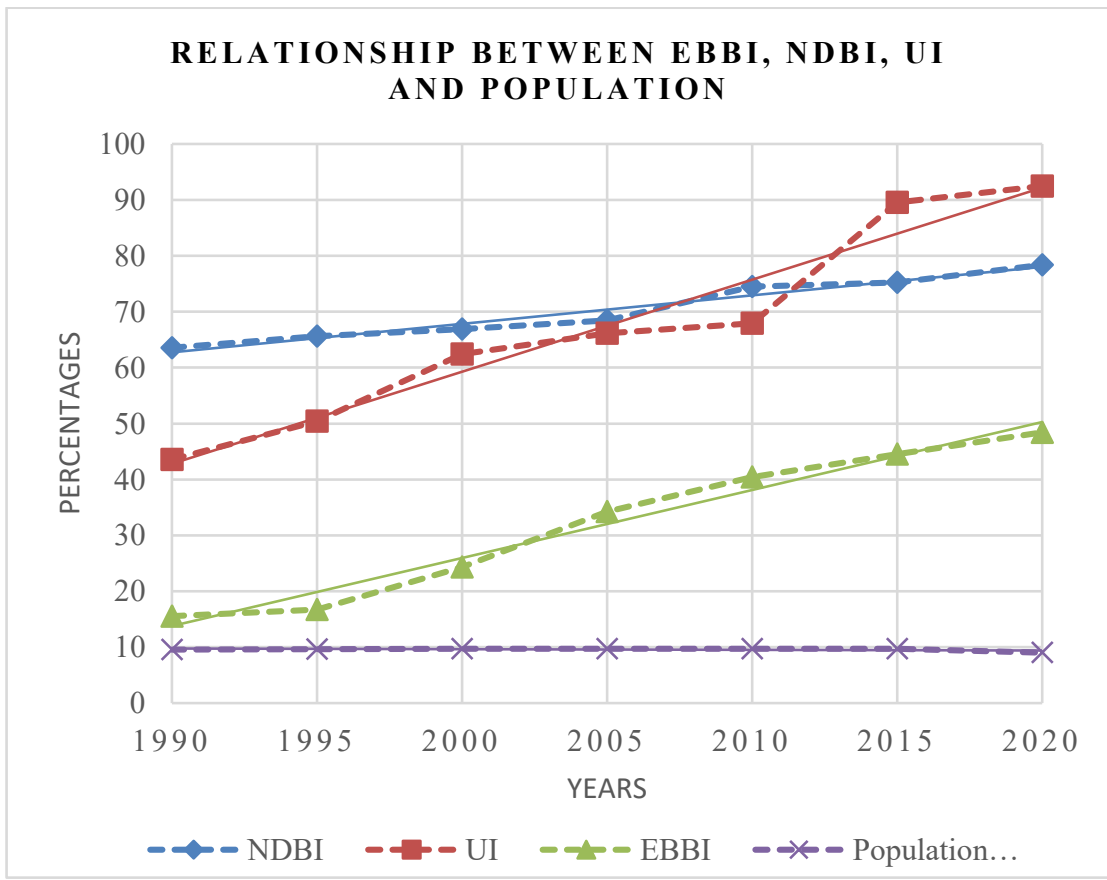

Figure 11: Relationship between EBBI, NDBI, UI and population rate

However, high spectral reflectance of built-up area in and the ability of TIR band to distinguish high and low levels of pixels allowed built-up area to be separated from barren land in EBBI image. Moreover, by taking the difference between index highlighting built-up area and bare land NDBI and NDVI for vegetation and water indices, separated the built-up area from vegetation and water, resulting in higher accuracy in case of UI. The overall accuracy image in built-up area extraction was found to be $93.2 \%$ and the correlation value is 0.97 , respectively, which was much higher than NDBI (overall accuracy $=78.4 \%$, correlation value $=0.95$ ) and the UI (overall accuracy $=92.4 \%$, correlation value $=0.94)$ images. The built-up areas as determined by each remote sensing indices and from the google map data starts form the year 2005 were compared to determine the difference in area 
accuracies until 2020. The analysis results showed that the total built-up area in 2020 obtained more than double from the built-up area in 1990.

However, the built-up area extracted from the other two indices (NDBI and UI were much higher respectively) as compared to Sentinel image based built-up area. Figure 11 shows the built-up area extracted from EBBI (proposed method) and the two commonly used built-up indices, normalized difference built-up index (NDBI) and the urban index (UI) for the year 1990 to 2020. The patterns of built-up area extraction were found similar in the three indexes thought the built-up area was more in case of NDBI and UI compared to EBBI. Due to the NDBI and UI cannot be distinguished between built-up and bare land and much of bare land area near with the built-up area has been mixed with the area being developed. And hence we analyzed between the increasing of enhanced built-up and population growth rate by correlation of the linear regression as final of the data analysis in the thirty years of the study area.

\section{Conclusion}

This paper analyzes the shift of linear regression characteristics of urban built-up and bare land area in central Yangon under the management of Yangon city development committee. It found that the rapid expansion of urban built-up areas in the past 30 years. Because of the lack of an urban policy during Myanmar's decades of authoritarian rule, the city's transformations, especially its slow and disorganized metropolitan since 2010, have presented new challenges to both the authorities and the people of Yangon. Inadequate road infrastructures, severe traffic congestion (due to the massive vehicles, the inadequate road infrastructures, and the city's expansion linked to its growth), lack of parking spaces, noise and air pollution, gentrification of the core city, and last but not least, insufficient housing supply and the more neoliberal policies are all issues that Yangon Municipality is dealing with. By analyzing the change of built-up area's expansion intensity and urban area usage from 1990 to 2000 was relatively increase even though there occurred the steadily increasing after 2005, and also the expansion rate obviously accelerated in recent ten years. The coupling analysis model was applied quantitatively analyze the coordinated development level between the urban built-up area among the three indexes and the increasing of population rate in the study area. This study evaluates between the rapid expansion and evolution of the built-up area of the city in recent thirty years and population rate and moreover, it provides a valuable reference for the method of urban development in the future. Due to the NDBI and UI cannot be distinguished between built-up and bare land and much of bare land area near with the built-up area has been mixed with the area being developed when the enhanced built-up area EBBI showed the only the expansion of builtup area in this study. Therefore, this study found more reliable outputs of modelling in EBBI and hence it showed the relationship of increasing of enhanced built-up area and population growth rate by modelling and find out the data in the thirty years of the study area. between built-up area changes in indices. However, our research still must be further improved with the event of future technologies, like the advance of remote sensing images accuracy and refinement of built-up area classification. We are going to also still concentrate on the indexes in the context of built-up development in the new era.

\section{Acknowledgements}

For this study, one of us would like to thank Thailand International Cooperation (TICA) for the supporting scholars to this degree. I feel grateful because of the exceptional support of my advisor, Asst. Prof. Dr. Wutjanun Muttitanon who looked over and guided on my working process.

\section{References}

Asy-syakur, A. R., Wayan S. A. and Wayan A. N., 2012, Enhanced Built-Up and Bareness Index (EBBI) for Mapping Built-Up and Bare Land in an Urban Area. Remote Sensing, Vol. 4, $2957-$ 2970.

Abler, R. F., 1988, The Application Of Geospatial And Remote Sensing Technologies for Monitoring the Implementation. Agenda 2063 and UN-SDGs, 50-53.

Aziz, M. A., 2014, Applying the Normalized Difference Built-Up Index to the Fayoum Oasis, Egypt (1984-2013). Remote Sensing and GIS Applied to Natural Resources and Population, Vol. 2, 53-66.

Bramhe, V. S., Ghosh, S. K. and Garg, P. K., 2018, Extraction of Built-up Areas Using Convolutional Neural Networks and Transfer Learning from Sentinel-2 Satellite Images, Int. Arch. Photogramm. Remote Sens. Spatial Inf. Sci., Vol. 2(3), 79-85.

Bhatti, S. S. and Tripathi, N. K., 2014, Built-up Area Extraction Using Landsat 8 OLI Imagery. GIS Science \& Remote Sensing, Vol. 51(4), 445467. [Available online at https://10.1080/15481603.2014.939539.htm].

Chen, B. and Huang, X., 2016, Multi-source Remotely Sensed Data Fusion For Improving 
Land Cover Classification. ISPRS Journal of Photogrammetry and Remote Sensing, Vol. 124, 27-39.

Ellis, E., 2019, Land-use and land-cover change; The Encyclopedia of Earth. [Available online at https://editors.eol.org/eoearth/wiki/Landuse_and_land-cover_change.htm].

Ettehadi, P. S., Sertel, E. and Alganci, U., 2019, Improved Urban Land Cover/Use Mapping Using Sentinel-2A Imagery. Conference: International Symposium on Applied Geoinformatics (ISAG-2019), Istanbul, Turkey, 296-301.

JICA Annual Report, 2017, The Union of Myanmar Final Report, 1: main text on March 2018, 2631. [Available online at. https://www.jica.go.jp/english/publications/reports/annual/20 17/c8h0vm0000bws721-att/2017_all.htm]

Landsat Science. Landsat 5 MSS and TM., 1999, Available online at. https://eos.com/findsatellite/landsat-5-mss/.htm]

Landsat Science. Landsat 7. ETM, Imaginary, 2013, Available online at. https://landsat.gsfc. nasa.gov/landsat-7/.htm]

Landsat Science. Landsat 8. OLI, Imaginary, 2016, Available online at. https://eos.com/findsatellite/landsat-8/.htm]

Masek G. J., Wulder, M. A., Markham, B., McCorkel, J., Crawford, C. J., Storey, J. and Jenstrom, D. T., 2000, Landsat 9: Empowering Open Science and Applications Through Continuity. Remote Sensing of Environment, Vol. 248, https://doi.org/10.1016/j.rse.2020.111968.

MIMU, Myanmar Information Management Unit, 2020, Yangon boundary of Yangon city development committee (YCDC), Ward boundaries Yangon City_mimu_v9.2.0,
Accessed date: Feb, 2020. [Available online at. http://geonode.themimu.info/layers/.htm]

Phiri, D. and Morgenorth, J., 2017, Developments in Landsat Land Cover Classification Methods: A Review, Remote Sensing, Vol. 9, 967-972.

Regional EST Forum, 2008, Third Regional EST Forum in Asia, Singapore, Accessed date: Mar 17-19, 2008[Available online at. http://www.uncrd.or.jp/index.php?page $=$ view $\&$ type $=13 \& n r=6$ $2 \&$ menu $=232 . \mathrm{htm}]$.

Sentinel Online. Sentinel 2A, 2019, Available online at. https://sentinel.esa.int/web/ sentinel/missions/sentinel-2.htm].

Sertel, E., Robock, A. and Ormeci, C.. 2010, Impacts of Land Cover Data Quality On Regional Climate Simulations. International Journal of Climatology, Vol. 30, 1942- 1953.

U.S. Geological Survey, 2013, Landsat Processing Details. [Available online at. http://landsat 8. usgs.gov/Landsat8_Using_Product.php].

World Population Census Data, 2020, World Demographics 2020 (Population, Age, Sex, Trends) - World meter. [Available online at. http://worldometers.info.htm ].

Yangon City Development Committee(YCDC), 2016, Map of districts and townships of Yangon, [Available online at. http://www.ycdc.gov$. \mathrm{mm} /$ content.php?page=townshipmap.htm] conto ur taken from Open Street Maps.

Yi, Z., Guang, Y., Shixin, W., Litao, W., Futao, W. and Xiongfei, L., 2014, A New Index for Mapping Built-Up and Bare Land Areas from Landsat-8 OLI Data. Remote Sensing Letters, Vol. 5(10), 862-871.

Zha, Y., Jingqing, G. and Ning, S., 2003, Use of Normalized Difference Built-Up Index in Automatically Mapping Urban Areas from TM Imagery. International Journal of Remote Sensing. Vol. 24(3), 583-594. 